\title{
FEMINISMO CAMPONÊSE POPULAR: A VOZ QUE VEM DO CAMPO
}

\author{
PEASANT AND POPULAR FEMINISM: THE VOICE FROM THE COUNTRYSIDE
}

\begin{abstract}
RESUMO
Este artigo tem como objetivo analisar uma nova proposta teórico-prática do feminismo intitulada de Feminismo Camponês e Popular. Para tal fim, adotou-se como marco metodológico a teoria interseccional feminista. Inicialmente, discorreuse acerca das suas origens e dos seus efeitos para a organização dos movimentos autônomos de mulheres do campo e movimentos sociais que se proponham a incluir a pauta de gênero nos seus debates. Na sequência, debruçou-se sobre como esse feminismo, urdido e proposto pelas próprias camponesas, está sendo construído. Por derradeiro, concluiu-se que a sua organicidade e referenciação às condições e singularidades campesinas ensejaram não apenas um novo norte para os movimentos feministas, como também para os próprios movimentos camponeses constituídos - e em construção.
\end{abstract}

Palavras-chave: Feminismos. Feminismo Camponês e Popular. Mulheres Camponesas.

\begin{abstract}
This article aims to analyze a new theoretical-practical proposal of feminism entitled Peasant and Popular Feminism. To this end, the feminist intersectional theory was adopted as a methodological framework. Initially, it was brought up about its origins and effects for the organization of autonomous movements of rural women and in social movements that propose to include the gender agenda in their debates. Afterwards, it observed how this feminism, reflected and proposed by the peasants themselves, is being built. Finally, it was concluded that its organicity and reference to the peasant conditions and singularities gave rise not only to a new direction for the feminist movements, but also for the constituted peasant movements themselves - and under construction.
\end{abstract}

Keywords: Feminisms. Peasant and Popular Feminism. Peasant Women.

\section{Introdução}

Com o aumento dos conflitos no campo, da desigualdade na distribuição por terras, do exacerbado número de agrotóxicos liberados no país e dos corriqueiros

Isabelle M. C. V. Chehab

Universidade Federal de Goiás - UFG. Email: ivchehab@gmail.com

Giovana N. Carvalho

Universidade Federal de Goiás - UFG. Email: giovananobrec@gmail.com 
crimes ambientais praticados pelas transnacionais, tem se tornado cada vez mais necessário que os movimentos sociais do campo se organizem na luta pela defesa dos seus territórios, pela soberania alimentar e pela preservação do meio ambiente. Nesse contexto, percebe-se também a importância da articulação e da resistência das mulheres do campo e de comunidades tradicionais, sejam elas ribeirinhas, quebradeiras de coco-babaçu, indígenas, quilombolas, extrativistas, posseiras e semterra.

Tal articulação resistente tem possibilitado aos movimentos sociais do campo, nos últimos anos, a inclusão da discussão sobre questões de gênero atreladas às ruralidades, assim como do exercício de sua liderança por mulheres, por meio dos quais os debates incidem, permeiam e espraiam acerca das maneiras de combater o atual sistema de desigualdades que se sustenta, em linhas gerais, a partir de uma estrutura patriarcal, capitalista, racista e classista.

É nesse cenário que emerge um feminismo camponês e popular, ou seja, um feminismo refletido e construído a partir da própria realidade das mulheres do campo, pautado na identidade da luta dos seus movimentos sociais rurais. Esse é um conceito que nasce no seio dos próprios movimentos e que vem sendo forjado, de maneira conjunta, pelas mulheres camponesas do Brasil - e da América Latina. Tal feminismo guarda, portanto, raízes na prática da vida cotidiana das mulheres camponesas e se constitui como uma proposta alternativa - e revolucionária - à teoria construída pelo feminismo liberal hegemônico.

Nessa esteira, por intermédio da perspectiva da teoria da interseccionalidade, pode-se adentrar o debate dos limites desse feminismo hegemônico, na tentativa de compreender o papel desempenhado pelos diversos marcadores de opressão como estruturantes de uma sociedade capitalista.

Desse modo, aclara-se que o objetivo do presente não é exaurir a análise do Feminismo Camponês e Popular como uma "nova” teoria do feminismo, considerando sua concepção razoavelmente recente, sobre a qual se passou a discutir com mais intensidade na última década, e ainda em vias de construção e sistematização pelos próprios movimentos sociais. Propõe-se, sim, investigar o papel desse feminismo para a união e coordenação das mulheres camponesas, bem como para a estrutura organizacional dos movimentos sociais camponeses.

Para tanto, adotou-se o Movimento de Mulheres Camponesas - MMC como objeto de análise, observando a maneira como o Feminismo Camponês e Popular está sendo construído dentro desse movimento, visando compreender, pois, de que modo ele tem contribuído no fortalecimento das próprias reivindicações das comunidades rurais. Justifica-se tal escolha pelo fato de o MMC ter sido o primeiro movimento da Coordenadoria Latino-Americana de Organizações do Campo CLOC/Via Campesina a se declarar como feminista, o que ensejou um amplo debate sobre a proposta de um feminismo que tivesse sua raiz teórico-prática baseada nas mulheres camponesas.

Destarte, entende-se como essencial compreender o motivo dessa nova proposta de feminismo não se coadunar com o que cotidianamente é defendido pelo 
feminismo liberal, que considera a mulher como uma categoria universal e, por via consequente, subestima o gênero como uma categoria de opressão que se sobrepõe às outras.

Ao final, destaca-se que foi realizada uma pesquisa bibliográfica acerca das teorias feministas consideradas hegemônicas, assim como do Movimento de Mulheres Camponesas e do surgimento do Feminismo Camponês e Popular - enquanto nova proposta teórico-prática nos estudos de gênero. Ressalta-se, ainda, que a análise interseccional feminista foi aqui utilizada como método de interpretação, conforme adiante será explicitado.

\section{Os limites do feminismo hegemônico}

Ao se debruçar sobre o contexto histórico do movimento feminista, tem-se que o "feminismo hegemônico", de matriz liberal, ou seja, aquele pautado em uma visão eurocêntrica, no qual o centro do movimento foi ocupado pela mulher branca, intelectual, de classe média, urbana e suas respectivas pautas, constituiu-se como predominante na América Latina e, principalmente, no Brasil.

Nesse diapasão, Cláudia Cardozo (2014) expõe o pensamento de Lélia Gonzalez, quem sempre urdiu duras críticas ao feminismo hegemônico, como também buscou evidenciar a história e a resistência das mulheres negras e indígenas - no Brasil e na América Latina. Foi Gonzalez, igualmente, a responsável pelo pioneirismo na discussão da descolonização do saber e da produção de conhecimento, ao questionar a insuficiência das categorias analíticas das Ciências Sociais para alcançar a realidade das mulheres negras. Sustentava que, para estruturar a colonização, o colonizador se utilizou justamente do racismo, como uma forma de justificar a sua intervenção, criando, assim, uma suposta superioridade do colonizador. Enfrentando tal pensamento, Gonzalez propôs, então, uma desconstrução das estruturas que possibilitaram a manutenção da colonialidade do saber (Cardozo, 2014).

Desse modo, entendendo que a desigualdade sexual, na América Latina, em particular, se articula muito bem dentro dos quadros das desigualdades raciais, defendia que as mulheres amefricanas e ameríndias (categorias utilizadas por Lélia Gonzalez para determinar as mulheres não brancas) sofreriam discriminação em dobro: sexual e racial (Gonzalez, 1988). Essas mulheres seriam, pois, as "mais oprimidas e exploradas de uma região de capitalismo patriarcal-racista dependente" (Gonzalez, 1988: 138), no contexto de uma discriminação de caráter triplo, quando se conclui que, ao analisar a questão de classe, as ameríndias e amefricanas eram, em sua maioria, também, parte do proletariado (Gonzalez, 1988).

Historicamente, tem-se que o modelo entendido como padrão e valorizado na sociedade é o branco, e que o racismo foi constituído justamente a partir da superioridade desse padrão branco e patriarcal, o qual a teoria feminista acabou 
incorporando em suas pautas, reinvindicações e discursos, resultando no fato da mulher branca como centro do movimento feminista durante muito tempo.

Ao encontro disso, bell hooks afirma que:

Na América, o estatuto social das mulheres negras e brancas nunca foi o mesmo. No século XIX e no início do século XX na América, poucas ou nenhumas semelhanças podem ser encontradas entre as experiências de vida desses dois grupos femininos. Apesar de ambos serem sujeitos à vitimização sexista, como vítimas de racismo as mulheres negras foram sujeitas a opressões que nenhuma mulher branca foi forçada a suportar. De facto, o imperialismo racial branco garantiu a todas as mulheres brancas, embora vitimizadas pela opressão sexista, o direito em assumir o papel de opressora na relação com as mulheres negras e com os homens negros (hooks, 1981: 89).

De fato, o movimento feminista trouxe à tona importantes discussões ao enfrentar e questionar o sistema patriarcal, escancarando a opressão sexista a qual as mulheres estavam submetidas. Mas, de quais mulheres exatamente se falava?

Enfrentar a discussão sobre opressão de raça ou classe, durante muito tempo, foi ignorado pelo próprio movimento feminista, que se pautou em uma agenda de reivindicações exclusivas de mulheres brancas e de classe média, ou seja, as mulheres negras e as mulheres brancas da classe trabalhadora, em regra, não tinham espaço nessa luta.

Nesses termos, Angela Davis (1981), em Mulheres, Raça e Classe, rememora o início da luta pelos direitos das mulheres nos EUA e, ao analisar raça e classe na campanha pelos direitos civis das mulheres, enfatiza o lado excludente e seletivo dessa luta. Discorrendo sobre a famosa Convenção de Seneca Falls - primeira convenção sobre os direitos da mulher nos Estados Unidos -, deixa claro que a Declaração dali advinda foi escrita com base nos interesses específicos de uma categoria de mulheres, a saber: mulheres da burguesia e da classe média emergente.

Destarte, Angela Davis (1981: 64) entende que:

Enquanto consumação exata da consciência do dilema das mulheres brancas de classe média, a declaração ignorava totalmente a difícil situação das mulheres brancas da classe trabalhadora, bem como a condição das mulheres negras tanto do Sul como do Norte.

Posteriormente, Davis, igualmente, denuncia o racismo dentro do próprio movimento sufragista, já que, apesar de grande fração das sufragistas se considerarem abolicionistas, muitas se colocaram contra o alcance de todos os direitos civis por parte da população negra, visto que acreditavam fielmente que a 
extensão do sufrágio aos homens negros, por exemplo, os tornaria superiores a elas (Davis, 1981: 81).

Por via consequente, esse viés eurocentrista, presente no feminismo brasileiro, projetou uma ignorância à urgência de ter raça, classe e etnia como ponto central da questão juntamente com as hierarquias de gênero. Tal omissão fez com que o feminismo resultasse, portanto, e cada vez mais, em um movimento que, infelizmente, universalizava o conceito de mulher.

Nessa esteira, percebe-se que o feminismo hegemônico privilegia pautas que dizem respeito apenas à opressão sexista. Não é à toa que as discussões mais "populares" do feminismo entre as mulheres brancas e de classe média/alta, ainda hoje, digam respeito, precipuamente, ao mito da fragilidade da mulher, da "rainha do lar" e da garantia das mesmas oportunidades no mercado de trabalho para homens e mulheres. Mas, novamente, de que mulheres estamos falando?

Eram esses os questionamentos que Sueli Carneiro também levantava e era enfática ao respondê-los:

Nós, mulheres negras, fazemos parte de um contingente de mulheres, provavelmente majoritário, que nunca reconheceram em si mesmas esse mito, porque nunca fomos tratadas como frágeis. Fazemos parte de um contingente de mulheres que trabalharam durante séculos como escravas nas lavouras ou nas ruas, como vendedoras, quituteiras, prostitutas... Mulheres que não entenderam nada quando as feministas disseram que as mulheres deveriam ganhar as ruas e trabalhar! Fazemos parte de um contingente de mulheres com identidade de objeto (Carneiro, 2011: 1).

Ora, a pauta das mulheres negras não pode ser a liberdade de "poder trabalhar onde quiser", haja vista que as mulheres negras sempre tiveram a sua força de trabalho explorada. A luta das mulheres negras era, pois, antecedente, uma vez que pugnavam pelo reconhecimento de sua existência enquanto indivíduos.

Dito isso, resta inconteste que as mulheres negras, indígenas e camponesas possuem demandas específicas, as quais, se tratadas apenas como uma questão de gênero, incorrem no risco de não conseguir atrelar o sexismo a outros tipos de dominação. Demonstra-se, assim, a insuficiência teórica do feminismo hegemônico para conseguir alcançar o contexto de mulheres em sociedades multirraciais e pluriculturais, como as da América Latina.

É nesse sentido que se fala da existência de feminismos, justamente por reconhecer as diferenças e pluralidades que existem entre as mulheres. O plural aqui nos ajuda a demonstrar, em última análise, a necessidade de nos afastarmos de teorias que universalizam, e, consequentemente, tendem a invisibilizar a categoria "mulher". Infere-se, pois, a necessidade de se pensar propostas de feminismos a partir da teoria interseccional, ou seja, analisar as opressões de raça, gênero, classe e 
etnia atuando de maneira entrecruzada na vida dessas mulheres, formando, assim, uma estrutura de opressões.

Desse modo, Kimberlé Crenshaw (2002: 177) defende que:

A interseccionalidade é uma conceituação do problema que busca capturar as consequências estruturais e dinâmicas da interação entre dois ou mais eixos da subordinação. Ela trata especificamente da forma pela qual o racismo, o patriarcalismo, a opressão de classe e outros sistemas discriminatórios criam desigualdades básicas que estruturam as posições relativas de mulheres, raças, etnias, classes e outras.

No mesmo cenário, Djamila Ribeiro (2016: 3) aduz que se pautar na teoria da interseccionalidade feminista é entender que não há primazia de uma opressão sobre as outras, ou seja, precisamos perceber que as opressões são estruturantes, de maneira que, para combatê-las, é necessário romper com as suas próprias estruturas. Nessa senda, começaram a ser propostas, tanto no âmbito teórico, quanto no âmbito político, novas abordagens sobre o feminismo, que permitissem visibilizar narrativas, até então, subalternizadas pelo próprio movimento. Exemplo disso, são as mulheres rurais, que possuem narrativas próprias no contexto do campo, bem diferentes do contexto que as mulheres urbanas estão inseridas, por exemplo.

Com esse norte, o Caderno de Conflitos no Campo da Comissão Pastoral da Terra (CPT) (2018) dedicou um capítulo exclusivo para tratar da abordagem do silenciamento das mulheres camponesas. Segundo dados colhidos pela CPT, entre os anos de 2009 e 2018, 1.409 mulheres do campo sofreram algum tipo de violência. Com mais exatidão, 38 mulheres foram assassinadas, 80 sofreram tentativas de assassinato, 409 receberam ameaças de morte, 22 morreram em consequência de conflitos, 111 foram presas, 410 foram detidas e 37 foram estupradas.

A partir desses números, percebe-se que as mulheres do campo, além de enfrentarem mais dificuldades que os homens com relação ao acesso à terra, à água, a sementes, à tecnologia e à assistência técnica, são as maiores vítimas da violência e exploração sexual, principalmente como consequência da instalação de projetos de desenvolvimento, como hidrelétricas (CPT, 2018: 84).

É, portanto, nesse contexto de silenciamento das pautas e das particularidades dessas mulheres, que surgem organizações autônomas de mulheres camponesas, unidas pela luta contra um projeto de desenvolvimento capitalista e predatório, as quais se configuram como um dos catalisadores dos conflitos socioambientais. $\mathrm{O}$ Movimento de Mulheres Camponesas é um desses movimentos e é no seio desse movimento que se propõe forjar um feminismo, simultaneamente, popular e camponês. 


\section{Movimento de mulheres camponesas}

A partir dos anos 1970, as lutas progressistas do campo contra a ditadura civil-militar tomaram conta do país, quando da mesma forma foram fortalecidos os movimentos populares, sindicatos combativos e partidos políticos de bases populares. Nesse período, por causa da exacerbação das relações capitalistas, racistas e patriarcais, a participação das mulheres foi ainda mais invisibilizada, tema que seria pautado durante o I Encontro Nacional das Trabalhadoras Rurais, em 1986, quando as mulheres afirmaram que não tinham espaço na tomada de decisões, sobejandolhes, apenas, um papel secundário na luta (MMC, 2018: 5).

Ao perceberem que não conseguiam encontrar seu espaço por meio das ferramentas de luta já existentes, as mulheres entenderam que a sua luta precisava ser protagonizada distintamente, combatendo de frente o sistema existente, de ordem capitalista, patriarcal e racista. Esse é um dos principais motivos para que, durante os anos 8o, as mulheres camponesas, em específico, passassem a se organizar em vários grupos, associações, organizações e movimentos autônomos, com o objetivo de alavancar sua própria luta.

Nessa toada, em 1986, foi organizado o I Encontro Nacional de Mulheres Trabalhadoras Rurais, onde mulheres de 16 estados tinham como objetivo discutir as pautas das mulheres camponesas no país. As mulheres, então, definiram as diretrizes de lutas que passariam a seguir, como a luta por uma maior participação política.

Nove anos depois, em 1995, foi criada a Articulação Nacional de Mulheres Trabalhadoras Rurais, que reuniu mulheres dos movimentos autônomos, a exemplo da Comissão Pastoral da Terra (CPT), Movimento dos Trabalhadores Rurais Sem Terra (MST), Pastoral da Juventude Rural (PJR), Movimento dos Atingidos pelas Barragens (MAB) e Movimento dos Pequenos Agricultores (MPA) (MMC, online).

Tal conduta desencadeou a organização de mulheres camponesas em diferentes estados brasileiros, o que posteriormente indicaria a necessidade de um movimento autônomo e de caráter nacional. O Movimento de Mulheres Camponesas (MMC) propriamente dito passou a ter esse nome em 2004, resultado da união desses vários movimentos autônomos de mulheres que já existiam em diversos estados. Desde então, o Movimento entende-se como autônomo, de base, de classe, feminista, camponês e popular (MMC, 2018: 6). É autônomo, na medida em que são as próprias mulheres que fazem parte do movimento e que decidem a sua agenda de luta. É de base, porque a organização dessas mulheres advém dos grupos de base constituídos nas comunidades rurais. É de classe, considerando que o movimento afirma ser pertencente também a classe trabalhadora. É feminista, já que incorpora no movimento a luta pelo fim das desigualdades de gênero. É camponês, porque o movimento gira em torno da organização e luta das mulheres camponesas. Por fim, é popular, porque um dos projetos do movimento é a construção de uma sociedade socialista, na busca por um projeto popular de país (MMC, 2018). 
Portanto, afirma-se que o movimento surgiu, principalmente, para trazer visibilidade às questões das mulheres da roça que não se viam representadas em outros tipos de movimentos, sejam eles o sindicato de trabalhadoras rurais, os movimentos populares mistos, entre outros. Tais movimentos tinham pautas específicas, que não contemplavam nem reconheciam por inteiro as reinvindicações das mulheres camponesas (Calaça \& Conte \& Cinelli, 2018: 5).

$\mathrm{O}$ MMC, assim como outros movimentos sociais, possui igualmente uma mística e uma simbologia. É na bandeira do movimento que logo se consegue perceber a presença da simbologia; ali, a cor predominante é o lilás, conhecida popularmente por representar o feminismo e simbolizar a inteligência. Além da cor, há, ainda, outros símbolos na bandeira, como a cesta de alimentos, que significa a produção no campo e a criança, representando o ciclo de reprodução da vida. Já o chapéu e o lenço se referem à mulher rural; a enxada na mão da mulher representa aquele que é um dos principais instrumentos de trabalho e simboliza o esforço dessas mulheres. Ademais, na bandeira, verificam-se as imagens de três mulheres, sendo uma indígena, uma negra e outra branca, concernentes às três principais origens étnicas presentes no país (Táboas, 2014: 22).

No endereço eletrônico do MMC, encontram-se inúmeras informações sobre o movimento, entendendo-o como a forma mais rápida de difundi-las. Neste, podemos achar as principais lutas, ou melhor, "bandeiras de luta", como as mulheres camponesas intitulam. O movimento gira em torno de quatro movimentos de luta centrais: Projeto Popular de Agricultura Camponesa; Ampliação dos Direitos Sociais; Projeto Popular para o Brasil; e Participação política da mulher na sociedade (MMC, online).

A bandeira por um "Projeto Popular de Agricultura Camponesa" abriga muitas pautas, dentre elas, destacam-se algumas: viabilização de políticas públicas para a agricultura, visando possibilitar a permanência no campo, uma maior produção de alimentos saudáveis e crédito especial para mulheres; pelo respeito e pela preservação do meio ambiente; pelo uso sustentável dos recursos naturais; recuperação, preservação e multiplicação das plantas medicinais e sementes crioulas; produção agroecológica de alimento etc. A bandeira pela "Ampliação dos Direitos Sociais" tem como pautas, por exemplo: a garantia do direito à previdência pública e universal; pelo direito à saúde pública, integral de qualidade; pela garantia da documentação; pelo direito de acesso à educação pública de qualidade; garantia de políticas públicas de combate à violência e proteção de mulheres e crianças etc. A bandeira que leva como lema um "Projeto Popular para o Brasil" defende que o MMC possui como objetivo central lutar pela soberania nacional, proteção e conservação da biodiversidade, por isso lutam: contra as políticas impostas pelo FMI, contra a ALCA, contra os transgênicos, contra todo tipo de discriminação e racismo. A quarta - e última - bandeira de luta é a "Participação política da mulher na sociedade", na qual as pautas giram em torno da participação, valorização e autonomia da mulher em todos os espaços de decisão, de maneira a garantir a manutenção e o avanço do 
campesinato; e a não mercantilização do corpo da mulher com o fim de todas as formas de violência e opressão praticadas para com as mulheres.

A partir dessas informações, fica claro que o MMC possui uma organização interna muito robusta e consistente, tendo tais bandeiras de luta importância central na facilitação da organização dessas mulheres e no fortalecimento do movimento, a saber:

O MMC construiu um programa de lutas, um projeto político, que pauta a autonomia da mulher em espaços de decisão sobre a produção e as relações humanas, que busca fortalecer o campesinato, a agroecologia e valorizar sua cultura e o saber popular [...]. São essas bandeiras de luta que motivam a união das mulheres camponesas em torno de uma mesma organização, de um mesmo projeto (Táboas, 2014: 30).

Nessa senda, é importante compreender a ressignificação que o próprio movimento traz ao termo "campesinato". Esse termo aparecia em alguns estudos como sendo um modo "atrasado" de produzir, como se a agricultura camponesa estivesse na retaguarda dos demais tipos de produção e/ou precisasse se modernizar. Entretanto, as mulheres do MMC exibem outra visão, claramente dissonante da concepção de atrelar o conceito de camponês a algo "atrasado".

Desse modo, a própria ressignificação do conceito elaborado pelo movimento em questão "[s]erviu para que se conseguisse abranger a diversidade de participantes, já existentes ou potências, dentro do movimento" (Boni, 2013: 72), considerando a pluralidade dos sujeitos para os quais o movimento se endereça, sendo aqui as mulheres do campo. Passa-se, então, a ser adotado um "significado de luta para o conceito de campesinato e a ideia de uma agricultura camponesa associada à agroecologia" (Boni, 2013: 74).

Tem-se, portanto, que a categoria campesinato é lida, pelo MMC, a partir de uma perspectiva que entende a relação de três elementos: a razão produtiva, concentrada nas necessidades imediatas de consumo; a análise do território, como sendo além de um espaço geográfico, um espaço, igualmente, político e cultural; e um projeto político, de ordem contra hegemônica. A união desses elementos tem, assim, como resultado, a possibilidade da reunião de mulheres, dos mais diversos segmentos, em torno de uma mesma categoria (Táboas, 2014: 41).

Isso fica explícito no endereço eletrônico do movimento, pois, ao definir quem faz parte dele, deixa claro que esse movimento é composto por mulheres camponesas, caracterizadas ali como "[a]quela que, de uma ou de outra maneira, produz o alimento e garante a subsistência da família” (MMC, online), sendo elas: agricultoras, arrendatárias, meeiras, ribeirinhas, posseira, boias-frias, diaristas, parceiras, extrativistas, quebradeiras de coco babaçu, pescadoras artesanais, semterra e assentadas. 


\section{Feminismo camponês e popular}

Nos últimos anos, tem havido uma tendência crescente das ofensivas contra as mulheres do campo, muito por conta da ampliação dos conflitos socioambientais territoriais, como também pela defesa do território de comunidades tradicionais, que, por sua vez, tem sido, cada vez mais, protagonizada por mulheres.

Segundo dados da CPT (2018), referentes ao ano de 2018, 486 mulheres sofreram algum tipo de violência - como tortura, agressão, tentativa de assassinato, aborto, intimidação, entre outros - em conflitos ocorridos no campo. Apesar desse número assustador, sabemos que tal violência é, no mais das vezes, invisibilizada, prova disso é que pouco se fala nos grandes veículos das mídias nacionais a respeito do que acontece no meio rural do país, muito menos do contexto em que as mulheres rurais vivem. Isso demonstra que há um grande - e deliberado -silenciamento das vozes que vêm do campo, principalmente se elas forem de mulheres, o qual precisa ser enfrentado.

Desse modo, as mulheres do campo, organizadas nos mais diversos movimentos sociais voltados para o contexto rural, percebem a urgência de romper com esse silenciamento, causado, sobretudo, pelo modelo de desenvolvimento da sociedade capitalista. Por outro lado, pode-se dizer que a negação do modo de vida, dos conhecimentos, das reivindicações e das lutas travadas pelos camponeses são naturalizados e alimentados, justamente, por esse tipo de desenvolvimento.

Ademais, não deve ser olvidado que essa negação do modo de vida das mulheres camponesas perpassa, em grande medida, a desvalorização do trabalho e da tripla jornada a qual elas são submetidas, a saber:

A realidade das mulheres pequenas agricultoras, camponesas e dos povos que vivem na floresta, é atingida diretamente com a sobrecarga e a não valorização de seu trabalho na sociedade capitalista, a qual não valoriza a agricultura familiar e a agroecologia e pela cultura machista, que não reconhece a sua tripla jornada de trabalho (Táboas, 2014: 55).

Outro dado de valia é que o MMC, antes mesmo de fazer parta da Via Campesina Brasil, já era aliado da Coordenação Latino-americana de Organizações do Campo - CLOC, sendo o seu primeiro movimento a se considerar feminista, trazendo tal debate para dentro das reuniões da articulação. Tendo sido, pois, na CLOC que o Feminismo Popular e Camponês foi proposto pela primeira vez, como uma forma de contemplar o feminismo das mulheres camponesas (Calaça \& Conte \& Cinelli, 2018: 10).

Entretanto, para o MMC se autodenominar como um movimento igualmente feminista em sua essência, não foi uma tarefa fácil. Sabe-se que o feminismo hegemônico, dados os seus limites teórico e político, claramente não conseguiu 
chegar nos setores populares urbanos, tampouco no âmbito rural, pois além de não representar as pautas, anseios e reinvindicações dessas mulheres, não as permitia construir uma diversidade dentro do movimento. Nessa senda, a "primeira impressão" do feminismo - e do que ele se propõe - acabou afastando essas mulheres, fazendo com que elas não se reconhecessem como feministas, mesmo tendo práticas visivelmente feministas.

Desse modo, o MMC levou certo tempo para se considerar, de fato, como um movimento de base feminista. "Não foi ninguém que buscou convencer as camponesas de que sua luta era feminista, foi a luta e análise da sua própria realidade que as levou a perceberem-se como parte de um instrumento maior de luta das mulheres" (Calaça \& Conte \& Cinelli, 2018: 13).

Com o transcurso temporal, verificou-se uma mudança de postura no que diz respeito à coletividade de vários movimentos sociais do campo, como a do próprio Movimento de Mulheres Camponesas. Atualmente, esse movimento não teme mais ao se declarar feminista, pois entendeu que poderia ressignificar não só o conceito de camponês, tornando-o uma categoria de resistência e acolhedor da diversidade, como também poderia fazê-lo em relação ao feminismo, a partir da realidade camponesa (MMC, online).

Nesse ponto, é relevante explicitar que, com a expressão "ressignificar o feminismo", pretende-se dizer que as mulheres camponesas começam a pensar o "ser feminista”, não partindo de um feminismo hegemônico, o qual mais as afastava do que as aproximava. Agora, elas passaram a construir um feminismo que contempla a realidade e o contexto em que estão inseridas, buscando demonstrar como é possível surgir uma proposta de feminismo no seio das próprias organizações autônomas de mulheres camponesas.

Para o MMC (2018: 30), o Feminismo Camponês e Popular reflete a trajetória construída e as vivências das mulheres camponesas, porque é nele que elas se encontram e se percebem como sujeito de direitos. É, ainda, a partir desse feminismo que as mulheres envolvidas no movimento passam a questionar tudo que antes era invisibilizado ou naturalizado pela sociedade. Refletem, assim, acerca das questões de gênero, raça, classe, etnia, deixando claro que lutam e acreditam na superação dessas opressões.

Por seu turno, essa proposta teórico-prática de feminismo dialoga com a existência de outras opressões que atingem as mulheres, para além da opressão de gênero. Assim, considera-se que analisar o contexto de desigualdades como advindas somente da opressão de gênero reduz-se a discussão e silenciam-se as consequências do entrecruzamento dos demais tipos de opressão.

Um olhar interseccional pode nos possibilitar compreender que a combinação de opressões que atingem as mulheres camponesas ajuda a estruturar o capitalismo. Dessa maneira, a luta dessas mulheres é justamente para romper com essa estrutura de opressões: 
O Feminismo Camponês e Popular é forjado na luta cotidiana de resistência e enfrentamento ao capitalismo, particularmente em sua expressão no campo. Construímos a partir da luta contra o agronegócio na defesa da natureza, dos bens naturais, contra os agrotóxicos e os transgênicos, contra o roubo e sangue de nossos territórios e terras. É assim que as ações de lutas das mulheres contra os latifundiários, contra as empresas do agronegócio, de enfretamento do Estado e contra sua repressão e criminalização da luta das mulheres camponesas faz parte da história e da formação da luta feminista camponesa e popular (MMC, 2018: 34).

Observa-se, portanto, que o Feminismo Camponês e Popular é, igualmente, um instrumento político, que busca a emancipação das mulheres camponesas. As mulheres que participam de movimentos organizados na CLOC afirmam que a concentração de terras é um elemento que contribui na acumulação de capital, porém, além disso, há o projeto de montar um modelo de produção que não se coaduna com o realizado pelos camponeses. Esse feminismo possibilita, portanto, o protagonismo das camponesas no "estabelecimento de novas relações de produção, mas também novas formas de relação entre homens e mulheres, relações que superem a subordinação, dominação e exploração de mulheres" (Seibert \& Rodrigues, 2017: 11).

Deve ser frisado que o Feminismo Camponês e Popular não se origina de uma construção teórica no seio da academia, mas da teoria e da prática urdidas dentro dos movimentos de mulheres camponesas na América Latina, sendo adotado como um instrumento de emancipação dessas mulheres. Assim, "[é] uma construção prática e teórica, assentada na materialidade da vida das mulheres camponesas, indígenas e negras latino-americanas, encerrada em suas pluralidades e diversidades" (Seibert \& Rodrigues, 2017: 15).

Compreende-se, assim, que tal expressão é um conceito ainda em construção, mas passa a ser essencial para entender a luta dessas mulheres. Diante disso, o Movimento de Mulheres Camponesas já realizou três seminários sobre o tema. $\mathrm{O}$ objetivo do encontro, intitulado "Seminário Internacional Feminismo Camponês e Popular", foi justamente avançar e aprofundar nos estudos sobre a temática, compartilhando experiências, vivências e debatendo sobre as opressões que estruturam o capitalismo, sempre levantando a bandeira de um projeto popular, socialista e classista.

No III seminário, o MMC conseguiu sistematizar as pautas que já haviam sido debatidas, de maneira que foram três os principais embasamentos e fundamentos do feminismo que esse movimento entendeu por adotar: Agroecologia como bandeira política; luta das mulheres e "nos reconhecermos", enfatizando que o processo de se autodenominar feminista é, por semelhante modo, um processo individual.

Na VI Assembleia de Mulheres da CLOC - Via Campesina, que ocorreu durante o VII Congresso da CLOC - Via Campesina, no mês de julho de 2019, sediado em Cuba, as mulheres camponesas se reuniram para debater a respeito da resistência dessas 
frentes ao sistema capitalista e patriarcal. No debate, reafirmaram a necessidade de se aprofundar nos eixos de poder que são estruturantes para o capitalismo, sejam eles: classe, raça, gênero, etnia, entre outros.

Durante estas dos décadas de formación sociopolítica hemos dedicado um afanoso estúdio a las categorias de género, classe y ético/raciales, comprediendo que las desigualdades que afectam a las mujeres son estructurales de uma sociedad capitalista, patriarcal, colonialista y racista. Estamos ciertas que no se puede eliminar la opresión, dominación y explotación de género y racial sin eliminar la opresión de classe (La Via Campesina, 2019, online).

Ainda na Declaração das Mulheres Camponesas na Assembleia da CLOC (2019), afirmaram que a construção desse feminismo emerge dos territórios e dos povos do campo, onde o debate se une à ação e à luta. Entretanto, as mulheres da CLOC apontam como desafios a questão de construir uma unidade e aliança a partir dos movimentos; e continuar a formação política de base, ampliando o debate sobre a fundamentação da proposta de uma sociedade socialista, com consciência de gênero (La Via Campesina, 2019, online).

Nessa senda, observa-se que um dos pontos que singulariza o projeto do Feminismo Popular Camponês é que este, ao contrário de outras concepções feministas, busca a emancipação das mulheres como sujeitos coletivos, não partindo de uma concepção de libertação das mulheres, apenas, no que tange aos seus direitos individuais.

\section{Considerações finais}

Verificou-se que o feminismo hegemônico encontra o seu limite naquilo que sua teoria não consegue responder e nas mulheres - e vivências - singulares que ele não consegue contemplar, sobretudo para aquelas sujeitas à opressão de raça e classe, para além da opressão de gênero. Considerar a mulher como uma categoria universal, típico de algumas vertentes do feminismo, silencia mulheres que não correspondem a um padrão eurocêntrico e ignora outros tipos de opressão.

Pensar em um feminismo que emerge da organização dos movimentos sociais do campo da América Latina, a partir da realidade vivenciada dia após dia pelas mulheres camponesas, é buscar entender, de maneira genuína, a diversidade dentro do próprio movimento feminista. Isso, possibilitando, inclusive, um pensamento decolonial e interseccional, dentro do feminismo, capaz de respeitar e reconhecer as diferenças entre as mulheres.

A partir de uma teoria interseccional, consegue-se entender as propostas de feminismos que surgem, buscando demonstrar que não é só o gênero que demarca desigualdade, sendo essencial analisar os outros eixos de poder que atuam em relação 
ao corpo e à vida dessas mulheres. Destarte, percebe-se a proposta do Feminismo Camponês e Popular como uma forma de alcançar os inúmeros, diversos e silenciados contextos em que as mulheres camponesas estão inseridas, entendendo que estas ressignificaram não somente o conceito de campesinato, como também o conceito do que era ser feminista para elas.

Desse modo, essa "nova" categoria que as mulheres camponesas estão construindo tem contribuído diretamente para a auto-organização dos movimentos sociais do campo, colocando sempre em debate que não há como lutar por um projeto popular para o país sem pensar na emancipação das mulheres. Por tal norte, igualmente, acreditam no Feminismo Camponês e Popular como um instrumento político.

Como foi dito no início deste artigo, o objetivo não era exaurir a temática proposta, mas, sim, colaborar com/para o debate acerca do Feminismo Camponês e Popular. Considera-se que essa categoria, que surgiu dentro da organização de movimentos sociais camponeses da América Latina, ainda está em construção teórico-prática, sendo fundamental que se lance um olhar minucioso sobre como as mulheres camponesas estão tecendo esse feminismo e, simultaneamente, elaborando/ colaborando para a sua aproximação com a academia.

\section{0}

\section{Referências}

BONI, Valdete. (2013). "Movimento de Mulheres Camponesas: Um movimento camponês e feminista”. Revista Grifos. n. 34/35, p. 67-88.

CALAÇA, Michela \& CONTE, Isaura \& CINELLI, Catiane. (2018). "Feminismo camponês e popular: uma história de construções coletivas". Revista Brasileira de Educação do Campo. v. 3, n. 4, p. 11156-1183.

CARDOZO, Cláudia. (2014). "Amefricanizando o feminismo: o pensamento de Lélia Gonzalez”. Revista Estudos Feministas, Florianópolis, 22(3): 320. p. 965-986.

CARNEIRO, Sueli. (2011). "Enegrecer o feminismo: a situação da mulher negra na América Latina a partir de uma perspectiva de gênero”. Geledés [online]. São Paulo. Disponível em: <https://www.geledes.org.br/enegrecer-o-feminismo-situacao-damulher-negra-na-america-latina-partir-de-uma-perspectiva-de-genero/>. Acesso em: 15 jul. 2019.

COMISSÃO PASTORAL DA TERRA. Caderno de Conflitos do Campo. 2018. Disponível em: <https://www.cptnacional.org.br/component/jdownloads/send/41-conflitos-nocampo-brasil-publicacao/14154-conflitos-no-campo-brasil-2018?Itemid=o $>$. Acesso em: 15 jul. 2019. 
CRENSHAW, Kimberlé Williams (2002). "Documento para o encontro de especialistas em aspectos da discriminação racial relativos ao gênero”. Revista Estudos Feministas. v.10, n. 01, p. 171-188.

DAVIS, Angela. (2016). Mulheres, Raça e Classe. Trad. Heci Regina Candiani. São Paulo: Boitempo.

GONZALEZ, Lélia. (1988). "Por um feminismo afrolatinoamericano". Revista Isis Internacional, Santiago, v. 9, p. 133-141.

HOOKS, bell. (1981). "Racismo e feminismo: a questão da responsabilidade”. In: HOOKS, bell. Ain't I a woman: Black Woman and Feminism. Não sou eu uma mulher: Mulheres Negras e feminismo. Tradução livre para a Plataforma Gueto. Janeiro, 2014. p. 86-113.

LA VIA CAMPESINA. Declaración VI Asamblea de Mujeres Cloc - Vía Campesina. Disponível em: < https://viacampesina.org/es/declaracion-vi-asamblea-de-mujerescloc-via-campesina > Acesso em: 15 jul. 2019.

MMC BRASIL. Movimento de Mulheres Camponesas. 2010. Desenvolvido por MDA Comunicação Integrada. Disponível em: < http://www.mmcbrasil.com.br/site >. Acesso em: 15 jul. 2019.

MMC. Feminismo Camponês e Popular. (2018). Disponível em: <http://www. mmcbrasil.com.br/site/materiais/download/Cartilha_feminismo_campones_ popular-2018.pdf>. Acesso em: 15 jul. 2019.

RIBEIRO, Djamila. (2016). "Feminismo Negro para um Novo Marco Civilizatório". Revista Internacional de Direitos Humanos - SUR 24. v.13, n.24, p. 99 -104.

SEIBERT, Iridiani. RODRIGUES, Sandra. (2017). Aproximação teórica entre o feminismo camponês e popular e o marxismo latino-americano. In: SINGA, Curitiba. Anais do SINGA. Disponível em: <https://singa2017.files.wordpress.com/2017/12/ gto4_aproximaczа7сзазо-tecзbzrica-entre-o-feminismo-camponczaas-e-popular-eo-marxismo-latino-americano-1.pdf>. Acesso em: 15 jul. 2019.

TÁBOAS, Îsis. (2014). Viver sem violência doméstica e familiar: a práxis feminista do Movimento de Mulheres Camponesas. Dissertação. (Mestrado) - Programa de PósGraduação em Direitos Humanos e Cidadania do Centro de Estudos Avançados Multidisciplinares - Universidade de Brasília, Brasília, DF, Brasil.

Recebido em 07/05/2020.

Aceito em 15/o6/2020. 